\section{Laços perigosos entre machismo e violência}

Dangerous liaisons between

machismo and violence

\section{Maria Cecília de Souza Minayo 4}

Desde quando comecei a pesquisar o impacto da violência sobre a saúde, intriga-me a performance do "homem" no processo em que esse fenômeno social se desenrola. Estudando Meninos e meninas de rua (Minayo et al., 1993) lá estão eles como o grupo principal de exposição. Analisando a magnitude e a dinâmica dos infratores (Assis, 1999), os do sexo masculino são a maioria esmagadora. Observando os dados de mortalidade e de morbidade por acidentes (Minayo \& Souza, 2003), ei-los em primeiro lugar. Avaliando os óbitos por homicídios, ganham disparado como vítimas e agressores. Aprofundando as vulnerabilidades para uso de drogas, os homens correspondem à maioria dos usuários (Minayo \& Deslandes, 1998). E, ainda, nos casos de suicídios, são eles que estão na frente em sua própria destruição (Minayo \& Souza, 2003). Lendo um trabalho de Laurenti (1998) sobre a problemática da saúde do homem, toma-se conhecimento de que a desvantagem masculina está presente em relação à quase todas as causas específicas de mortalidade, quando comparada à situação feminina. E, completando o quadro, estudos de Mello Jorge, Gotlieb \& Laurenti (2001), confirmados por análises estatísticas do IBGE, ressaltam que a desvantagem do homem quando medida por expectativa de vida é de oito anos em relação à mulher, no contexto brasileiro atual.

Considero tais informações de alta relevância social e para a saúde e, por isso, parabenizo Lilia, Romeu e Márcia por terem assumido a responsabilidade de organizar este número temático que, com certeza, trará luz sobre vários aspectos das desvantagens masculinas quanto à saúde, a partir de análises epidemiológicas, sociológicas e culturais. Pessoalmente, ficarei muito feliz se este número temático der pelo menos dois frutos: 1) mostrar a relevância do tema homem na pauta dos estudos de gênero, tradicionalmente dominada por problemas femininos, sobretudo na área de saúde; e 2) propiciar da-

\footnotetext{
4 Claves-ENSP/Fiocruz. cecilia@claves.fiocruz.br.
}

dos para reflexão sobre propostas peculiares do setor para essa categoria, da mesma forma que se pensam cuidados de saúde para a mulher.

No papel de debatedora do texto redigido por Lilia, Romeu e Márcia, tentarei contribuir, discutindo alguns fundamentos que possam lançar luz sobre a questão das relações entre masculinidade e violência. Minhas reflexões têm como pano de fundo a problemática de gênero, historicamente construída, na qual se evidenciam, sem dúvida, expressões cabais do híbrido biológico-social (Latour, 1994). É nessa visão de híbrido que desenvolvo a discussão sobre masculinidade e violência, tendo como referência os textos de Roberto Connell (1987), Fonseca (1998), Machado (2001) e o próprio artigo em debate, dentre outros. Esses estudos historiam as falácias do essencialismo, do positivismo, e do normativismo presentes até hoje nas definições do senso comum e de muitos cientistas sociais sobre as relações entre homens e mulheres. Mas neles os autores também demonstram mudanças culturais e teóricas que estão ocorrendo, principalmente, promovidas e impulsionadas pelo movimento feminista e, de forma menos contundente, pela dinâmica dos vários grupos de liberação do homem.

Minha referência principal neste debate é Machado (2001) que focaliza, numa pesquisa antropológica, especificamente, as relações entre as formas de viver a masculinidade e a cultura da violência, tendo como parâmetro a análise de valores de longa duração que estruturam a cultura ocidental patriarcal e o que a autora denomina valores da alta modernidade correspondendo às mudanças da conjuntura atual. Machado trabalha o discurso e a performance de grupo de delinqüentes sociais apenados (estupradores, espancadores de mulheres, ladrões e assassinos), nos quais a autora encontra de forma aguçada os caracteres da cultura machista. A exacerbação do machismo nesse grupo o torna "bom para pensar" sobre o assunto, indo assim ao encontro da indagação que venho mantendo nesses anos de estudo da violência. $\mathrm{O}$ texto de Machado traz uma grande riqueza de detalhes que, pela exigüidade do espaço, deixarei de comentar, remetendo os leitores ao artigo completo.

A concepção do masculino como sujeito da sexualidade e o feminino como seu objeto é um valor de longa duração da cultura ocidental. $\mathrm{Na}$ visão arraigada no patriarcalismo, o masculino é ritualizado como o lugar da ação, da decisão, da chefia da rede de relações familiares e da pa- 
ternidade como sinônimo de provimento material: é o "impensado" e o "naturalizado" dos valores tradicionais de gênero. Da mesma forma e em conseqüência, o masculino é investido significativamente com a posição social (naturalizada) de agente do poder da violência, havendo, historicamente, uma relação direta entre as concepções vigentes de masculinidade e o exercício do domínio de pessoas, das guerras e das conquistas. $\mathrm{O}$ vocabulário militarista erudito e popular está recheado de expressões machistas, não havendo como separar um de outro. Levando em conta o caso brasileiro, típico da cultura ocidental e ao mesmo tempo específico em sua historicidade, comentarei três situações: a do estupro, a da violência contra a mulher na condição de cônjuge e a do homicídio cometido por homens contra homens.

No ato do estupro realiza-se superlativamente a dissociação entre o sujeito e o objeto da sexualidade, entre o apoderamento sexual do outro e a anulação da vontade da vítima. Machado (2001) comenta que todos os estupradores que entrevistou em sua pesquisa, apesar de confessarem que forçaram a relação sexual (o que teria sido feito como "uma fraqueza" ou "num momento de fraqueza"), no fundo acreditavam que a mulher queria ser violentada. Essa crença, de um lado insinua pelo menos duas coisas: 1) "macho mesmo", do ponto de vista sexual, deixa-se levar pela fraqueza, pois seus impulsos são tão fortes que ele não consegue controlá-los, por isso, "naturalmente" precisa ser compreendido e perdoado; 2) o "não" da mulher nunca deve ser considerado verdadeiro e sim parte do ritual de sedução. Portanto, a plenitude da macheza não admite que a mulher (em sendo objeto) possa dizer "não".

No caso das relações conjugais, a prática cultural do "normal masculino" como a posição do "macho social" apresenta suas atitudes e relações violentas como "atos corretivos". Por isso, em geral, quando acusados, os agressores reconhecem apenas "seus excessos" e não sua função disciplinar da qual se investem em nome de um poder e de uma lei que julgam encarnar. Geralmente quando narram seus comportamentos violentos, os maridos (ou parceiros) costumam dizer que primeiro buscam "avisar", "conversar" e depois, se não são obedecidos, "batem". Consideram, portanto, que as atitudes e ações de suas mulheres (e por extensão, de suas filhas) estão sempre distantes do comportamento ideal do qual se julgam guardiões e precisam garantir e controlar. A associação da mentalidade patriarcal que realiza e re-atualiza o controle das mulheres e a rivalidade presumida entre homens estão sempre presentes nas agressões por ciúme (medo da perda do objeto sexual e social) cujo ponto culminante são os homicídios pelas chamadas "razões de honra". No Brasil, "razão de honra" é uma categoria relacional forte e ao mesmo tempo provisória, pois sua existência, culturalmente, depende do exercício de vários papéis masculinos: o de provedor, o de pai e, sobretudo, o de marido que precisa assegurar a fidelidade da parceira no desafio com outros homens. Neste último caso evidencia-se uma contradição de termos, pois o homem "honrado" vive em eterna vigilância contra o homem "bicho danado" (Machado, 2001), e esses papéis podem ser trocados sempre, dependendo do olhar do outro. Como num jogo de espelhos, o "homem honrado" enxerga a masculinidade como o lugar dos instintos incontroláveis, da agressividade e da violência.

No mundo da criminalidade, a idéia fundante de macho violento se centra na mesma crença arraigada do masculino como o espaço da iniciativa, do poder e da imposição da vontade, fazendo a associação de dois planos, o da sexualidade e o da sociabilidade. A moral do macho violento é a da virilidade que se apodera do corpo, dos desejos, dos projetos, dos negócios e da vida do outro. Machado (2001) analisa essa dinâmica tomando como exemplo as falas de jovens infratores do Distrito Federal. A partir deles, busca entender os efeitos da pós-modernidade sobre a construção das categorias de masculinidade em associação com novas modalidades de violência. A autora evidencia a convivência de várias lógicas temporais fortemente presentes na sociabilidade violenta dos jovens infratores: 1) a permanência do machismo da "honra"; 2) o crescimento da consciência de direito, vivido no exagero do "individualismo das singularidades" (2001) que se expressa no culto da hiperliberdade individual per si; 3 ) a experiência da compressão do tempo-espaço pela valorização do tempo curto e rápido e 4) o culto do imediatismo nas vivências de prazer e sucesso.

Assim, o caminho para o uso das drogas, a participação em assaltos, os pegas de carro, o excesso de velocidade no trânsito, as mortes encomendadas e executadas como fato acabado, as ordens arbitrárias dadas às comunidades em que vivem e as instituições aí presentes por parte das gangues reafirmam a valorização do machismo de longa duração. Atualizam-se na identidade do "chefe do bando, do bonde, do gru- 
po", do "maioral", do "que faz e acontece", do que "mata, esquarteja e esfola", do que "humilha e tripudia sem dó nem piedade". Mas o machismo pós-moderno é um fenômeno novo que vive da velha cultura patriarcal e a reafirma nos "vícios" e "compulsões" da sociedade pós-tradicional, como lembra Giddens (1991; 1995). Sua performance violenta não é, necessariamente, contra um rival específico, o que ocorre freqüentemente nas expressões da violência tradicional. Ao contrário, exterioriza-se no exibicionismo, na vanglória, no prazer do domínio e na imposição da crueldade per si, corrompendo os valores cultivados na idéia do individualismo (Elias, 1994) como valor universal que promove a responsabilidade social e a solidariedade cidadã.

As conclusões de Machado já vinham sendo prenunciadas por autores como Giddens (1991; 1995), Minayo, (2003), Soares (2002), Zaluar (2002), Assis (1999) dentre outros. Esses estudiosos têm evidenciado o surgimento de novos tipos de subjetividade e de sociabilidade que respondem à expansão de uma sociedade consumista (Harvey, 1998), de espetáculo (Debord, 1997); narcisista (Lasch, 1979); de decadência do trabalho como valor e da compressão do espaço-tempo (Harvey, 1998).

Encerrando, preciso dizer que muitos pontos atinentes ao assunto em pauta nem foram tocados, porque eu quis focalizar e exemplificar expressões da violência brasileira, nas quais a maioria das vítimas e dos agressores é homem. Também não desenvolvi a discussão sobre as várias formas de masculinidade e nem tive oportunidade de enumerar as mudanças positivas trazidas pela pós-modernidade nas questões de gênero: essas também existem. Privei-me disso, porque, na exigüidade do espaço, preferi sublinhar a necessidade de aprofundamento de algumas questões de saúde vinculadas a estilos de vida. Para isso a reflexão sobre violência é exemplar, pois ela dramatiza causas (Arendt, 1994).

Para finalizar, aponto, sem medo de errar, dois instrumentos servindo ao machismo pósmoderno que se associa à violência que fere, provoca lesões e mata: 1) o carro, símbolo da potência, do tempo veloz e da hiperliberdade hedonista para os rapazes da classe média; 2) a arma de fogo, mediando a performance exibicionista de adolescentes e jovens das classes populares, que internalizaram o tempo curto da pós-modernidade como o contexto de seu rápido prazer e domínio. É claro que, tanto uns quanto outros (delinqüentes das classes populares e dos extratos médios) não constituem a totalidade da juventude brasileira e nem sua forma cotidiana de construir e vivenciar a realidade. Mas o pequeno número de rapazes que cria tanto sentimento de insegurança social evidencia que a violência é um problema complexo e fortemente arraigado na cultura e na sociabilidade nacional. "Fazendo muito barulho" e amedrontando, eles estão dizendo que sua performance não é apenas uma tempestade que vai passar, como um fenômeno da natureza. Ao contrário, a superação da violência é um desafio que exige muito investimento social, político e subjetivo para pensar e repensar a cultura brasileira.

\section{Referências bibliográficas}

Arendt H 1994. Sobre a violência. Editora Relume-Dumará, Rio de Janeiro.

Assis SG 1999. Traçando caminhos em uma sociedade violenta. Fiocruz, Rio de Janeiro.

Connell R 1987. Gender and power: society, the person and social politics. Stanford University Press, Stanford.

Debord G 1997. Comentários sobre a sociedade do espetáculo. Editora Contraponto, Rio de Janeiro.

Norbert E 1994. A sociedade dos indivíduos. Editora Jorge Zahar, Rio de Janeiro.

Fonseca AJMS 1998. A identidade masculina segundo Robert Bly. Tese de mestrado em Estudos Americanos. Universidade Aberta de Lisboa. UAL, Lisboa.

Giddens A 1991. As conseqüências da modernidade. Unesp, São Paulo.

Giddens A 1995. A vida em uma sociedade pós-tradicional, pp. 73-134. In A Gidens, U Beck \& A Lasch (orgs). Modernização reflexiva. Editora Unesp, São Paulo.

Harvey D 1998. A condição pós-moderna. Editora Loyola, São Paulo.

Lasch C 1979. A cultura do narcisismo. Warner Books, Nova York.

Latour B 1994. Jamais fomos modernos. Editora 34, Rio de Janeiro.

Laurenti R 1998. O perfil epidemiológico de saúde masculina na Região das Américas. Contribuição para o enfoque de gênero. Faculdade de Saúde Pública, São Paulo.

Machado LZ 2001. Masculinidades e violências. Gênero e mal-estar na sociedade contemporânea. Série Antropológica. UNB, Brasília. (Mimeo).

Mello Jorge MH, Gotlieb S \& Laurenti R 2001. A saúde no Brasil. Organização Pan-Americana da Saúde, Brasília.

Minayo MCS 2003. A violência dramatiza causas, pp. 2328. In MCS Minayo \& ER Souza (orgs). A violência sob o olhar da saúde. Fiocruz, Rio de Janeiro.

Minayo MCS \& Souza ER 2003. A violência sob o olhar da saúde. Fiocruz, Rio de Janeiro.

Minayo MCS (org.) 1993. Meninos e meninas de rua: o limite da exclusão social. Hucitec, São Paulo.

Minayo MCS \& Deslandes SF 1998. A complexidade das relações entre drogas, álcool e violência. Cadernos de Saúde Pública 14(1):35-42.

Soares LE 2002. Perspectiva de implantação de uma Política Nacional de Segurança Pública e de Combate à 
Violência, pp. 40-46. In Câmara dos Deputados (Coordenação de Publicações). Violência urbana e segurança pública. Câmara dos Deputados, Brasília.

Zaluar A 2002. Diagnóstico da violência urbana no Brasil, pp. 18-19. In Câmara dos Deputados (Coordenação de Publicações). Violência urbana e segurança pública. Câmara dos Deputados, Brasília.

\section{Homens e saúde: diversos sentidos em campo}

Men and health: several senses in field

\section{Pedro Nascimento 5}

Para mim é uma grande satisfação a oportunidade de participar deste debate que considero tão importante. Além da pertinência do tema que já valeria a empreitada, o artigo "Homens e saúde na pauta da Saúde Coletiva” consegue mapear diversas dimensões de um mesmo campo. Se por um lado essa amplitude deixa o debatedor com vontade de referir várias questões ao mesmo tempo - o que é aqui impossível; por outro, oferece ao leitor uma oportunidade ímpar de reflexão pelo que parabenizo os autores.

Também gostaria de situar minha fala: o lugar onde surgem meus questionamentos cruza a experiência de um antropólogo "iniciado" em bares junto de sujeitos que, reunidos, aprendiam a ser homens (Nascimento, 1995), com a experiência de uma pessoa que participa dessa discussão propondo um espaço para a reflexão sobre os homens nos campos aqui discutidos. Não se trata de reinstalar uma pouco produtiva oposição entre produção de conhecimento e ativismo, mas dizer dos dilemas próprios de um campo em construção (Medrado et al., 2000). A apresentação desses dilemas, a propósito, é o maior mérito deste artigo. São alguns deles, que particularmente me chamam a atenção, de que estarei tratando.

Uma primeira questão que destaco é que o artigo aponta para a necessidade de refletirmos o que estamos dizendo quando falamos gênero e estimula a busca da superação da reificação no feminino. Se parece que há acordo quando a referência é ao caráter histórico e cultural do

\footnotetext{
${ }^{5}$ Instituto Papai, Recife PE. pedro@papai.org.br
}

gênero, muitas vezes parece haver ainda pouca clareza quando se afirma que é a mesma sociedade que orienta a construção de elaborações consideradas masculinas e femininas. Se é igualmente inegável que sua característica básica é a assimetria de gênero, o que quero chamar a atenção aqui é que a forma como sujeitos vivenciam essa dimensão em suas vidas é constituinte tanto de mulheres quanto de homens.

É ainda desse campo de discussão uma outra questão trazida pelos autores que diz respeito à lógica dos benefícios indiretos para as mulheres da participação dos homens no campo saúde, sexualidade e reprodução. O caminho a ser percorrido para se compreender o que significa afinal falar-se em homens como sujeitos de direitos. Como pensar em direitos em relação a quem não só sempre usufruiu dos mesmos, como ainda impediu que outros - outras, as mulheres - assim se insurgissem? Caricaturas à parte, há um longo caminho para que consigamos dar o lugar devido ao fato de tratarmos dos homens, por um lado, como uma categoria genérica e universal e, por outro, falar dos sujeitos concretos do dia a dia.

Os autores enfrentam esse dilema o tempo todo. Referências a expressões como "masculinidade hegemônica", "padrões hegemônicos" etc., as quais são fundamentais para possibilitar mesmo a caracterização, trazem os riscos das generalizações e por isso os autores recomendam que não se pode desconsiderar a existência dos diferentes estilos de masculinidade, pois na vida cotidiana devemos levar em conta a posição concreta e particular dos sujeitos em cada grupo de referência. Isto, contudo, não é uma tarefa fácil, pois a referência ao modelo traz sempre a "tentação" da facilidade de achar que já conhecemos o que se nos apresenta antes mesmo de nos darmos ao trabalho de investigar a fundo suas múltiplas dimensões. Como não nos deslumbrarmos com a certeza tantas vezes repetida em diferentes espaços de que "os homens são assim"? Neste sentido, valorizar e dar visibilidade à diversidade dos sujeitos tem, por um lado, o apelo da pertinência metodológica e, por outro, a força da busca da superação dos estereótipos (Nascimento, 1999).

Uma outra questão tem a ver com a discussão sobre masculinidade e trabalho. A centralidade do trabalho na vida dos homens e na negociação de suas identidades; os desafios postos quando não são capazes de atualizar a prerrogativa de provimento financeiro do lar e mesmo a inconstância do trabalho precisam ser le- 